\title{
Process model for the successful implementation and demonstration of SME-based industry 4.0 showcases in global production networks
}

\author{
S. Peukert ${ }^{1} \cdot$ S. Treber $^{1} \cdot$ S. Balz ${ }^{1} \cdot$ B. Haefner ${ }^{1} \cdot$ G. Lanza $^{1}$ \\ Received: 11 October 2019 / Accepted: 21 January 2020 / Published online: 8 February 2020 \\ (c) The Author(s) 2020
}

\begin{abstract}
Small and medium-sized enterprises (SMEs), many of which operate as suppliers in global production networks (GPN), often times lack behind large enterprises in terms of Industry 4.0 implementation. For this reason, scientific contributions recommend SMEs to approach Industry 4.0 through pilot projects in which individual Industry 4.0 use cases are developed and implemented. Hence, to allow for a targeted development and implementation of Industry 4.0 use cases for SMEs in GPN, this paper proposes a five-step process model that seeks to make use of Industry 4.0 potentials in terms of increased product qualities and logistics performances within such networks. In contrast to existing process models, this paper follows a holistic approach that initially focuses on the identification of potential problems that impede increased product qualities and logistics performances. Building upon these problems, potential Industry 4.0 solutions are derived and transferred into use cases using a structured idea generation and selection process. After the successful implementation of the use case, the procedure is completed by the conversion of the use case into a showcase that might serve as a lighthouse project illustrating the potentials of Industry 4.0 for other production network partners. For testing its practicability, the procedure is exemplarily applied to the GPN of an automotive supplier.
\end{abstract}

Keywords Industry $4.0 \cdot$ Global production network $\cdot$ Process model $\cdot$ Maturity model

\section{Introduction}

In today's world, which is characterized by high dynamics and variances and an increasing individualization of products $[1,2]$, the economic advantages of implementing Industry 4.0 (I4.0) are almost undisputed. Believing the Germany Market Report and Outlook on Industry 4.0, the introduction of I4.0 promises a cumulative gross value added potential of up to 100 billion euros for Germany by 2025 [3]. This value added potential is thereby generally based on savings of up to $50 \%$ in various areas of production [4]. However, all companies within a globally operating production network are required to implement appropriate I4.0 technologies so that increases in customer satisfaction expected from I4.0 implementation take effect for the entire GPN [5]. As $99.6 \%$ of all companies in GPN are SMEs [6], these play a

S. Peukert

sina.peukert@kit.edu

1 wbk-Institute of Production Science, Karlsruhe Institute of Technology (KIT), Kaiserstr. 12, 76131 Karlsruhe, Germany particular crucial role in increasing the number of users of I4.0 technologies and hence in realizing I4.0 potentials for all network partners [7]. However, SMEs are the players where I4.0 is not yet sufficiently implemented [7].

Hence, new ways must be found that encourage SMEs to take the first step towards I4.0 in order not to lose connection with 14.0 role models. Therefore, scientific contributions recommend SMEs to approach 14.0 through pilot projects to gain experience [8, 9]. The resulting I4.0 use cases can subsequently serve as showcases being published on platforms such as the "Platform Industrie 4.0" to inspire other SMEs on their way towards I4.0 and to hence ensure an entirely increased prevalence of I4.0 within GPN. Consequently, the primary goal of this paper is to present a process model that supports SMEs in implementing I4.0 technologies to sustainably improve their product qualities and logistics performances, hence allowing for increased supplier qualities within the whole GPN and thus addressing a topic that has only found little attention so far. Relevant aspects of the generic process model thereby include the systematic analysis of the as-is-situation (e.g. by maturity assessments), the derivation of an I4.0 use case, the implementation of the 
use case and its transformation and commercialization as a showcase.

For reaching this goal, the remainder of this paper is structured as follows: Sect. 2 outlines relevant fundamentals and summarizes the existing state of the art for I4.0 process models and maturity indices. This way, major deficits of existing models and the unique selling points of the presented solution can be derived. Section 3 presents the developed model, while Sect. 4 exemplarily applies it to a use case from the automotive supplier industry. Section 5 condenses the gained insights.

\section{Fundamentals and state of the art}

As I4.0 is expected to yield promising results in terms of increased product qualities and logistics performances within GPN [10], the overall objective of the developed approach is to foster I4.0 implementation in these dimensions by means of exemplary use cases. GPN, on the one hand, can thereby be understood as a set of (globally) distributed production entities that contribute to value creation [11]. Production units are therefore linked by material, financial and information flows and supported by suppliers [11]. I4.0, on the other hand, is defined as a form of industrial value creation characterized by digitalization, automation and interdependencies among the involved partners affecting processes, products and business models of manufacturing enterprises $[4,12]$.

To embed I4.0 more strongly in GPN and to particularly qualify SMEs for a successful I4.0 implementation, structured procedures are recommended which can be repeated infinitely and adapted flexibly, hence allowing for the achievement of synergy effects and the realization of comparability of individual pilot projects. Process models thereby serve as an adequate means for taking such requirements into account. By definition, process models arrange methods and elements of project management into processes and phases of a standardized project flow [13]. They serve the purpose of transferring as-is-situations into defined target states using a structured approach with a defined number of steps [14]. Besides the logical sequence of steps, process models also provide methods and tools that are used as auxiliaries for realizing the target state [14].

As the overview of existing process models will reveal (Table 2), methods commonly taken into account include maturity indices, workshop concepts or creativity techniques such as brainstorming or the business model canvas. Thereby, maturity indices serve to describe indicatordependent development stages of an object of observation for a certain time period [15] and have been commonly applied for analyzing the degree of I4.0 implementation. By means of a literature review, several relevant I4.0 maturity indices have been identified which differ regarding the considered scope (technologies vs. whole value chains), survey method (intuitive online-self-assessments vs. cooperative assessments supported by consultants) and survey period (minutes vs. weeks).

In order to compare the indices in terms of their suitability for the process model developed in this paper, the criteria proposed by $[16,17]$ have been taken into account. They especially refer to I4.0 maturity assessments for SMEs and have proven to be meaningful. As shown in Table 1, they include: an intuitive methodology [16], low time and cost expenditures [16], adaptability [16], implementation orientation [17], interdisciplinarity [17] and objectivity/transparency [17]. However, as the focus of the developed procedure lies on a GPN perspective and on increased product qualities and logistics performances, these two criteria complement the list.

Comparing the indices in Table 1 regarding their suitability for the developed approach reveals that the Toolbox Industrie 4.0 [18] has the highest degree of fulfillment. Therefore, it will serve as a basis for the process model developed in Sect. 3. However, as the GPN perspective and the focus on increased product qualities and logistics performances have not found consideration in [18] up to now, it has to be adapted according to these requirements [19-21].

Apart from the presented maturity indices which serve as a starting point for the development of process models, the literature also contains a number of process models for I4.0 implementation. Among other things, these were analyzed to determine whether they were designed in such a way that they could be reused for this paper and whether they are easy to understand for the user. Furthermore, it was examined to what extent the models suggest a consistent solution that considers a procedure from initialization to demonstration. Based on the challenges described in Sect. 1, the focus should ultimately lie on the network perspective and consider the improvement of product qualities and logistics performances, hence allowing for improvements for the whole GPN. Figure 1 summarizes the requirements.

The existing process models have been identified in a systematic literature review using combinations of "Industrie 4.0", "Industry 4.0", "IoTS" or "Industrial Internet" and "guideline", "metamorphosis", "transformation", "roadmap", or "process model". Table 2 compares the emerged nine $\mathrm{I} 4.0$ process models and provides an idea of relevant components and methods.

A detailed examination thereby reveals that the existing process models are comparatively similar regarding their components (phases/milestones/methods/documents): Particularly, all models use well-described and detailed phases to clearly and understandably structure projects, hence allowing for userfriendliness and reusability. The individual phases are thereby comparable and range from preparation and analysis through 
Table 1 Evaluation of selected maturity indices (extending $[16] /[17])$

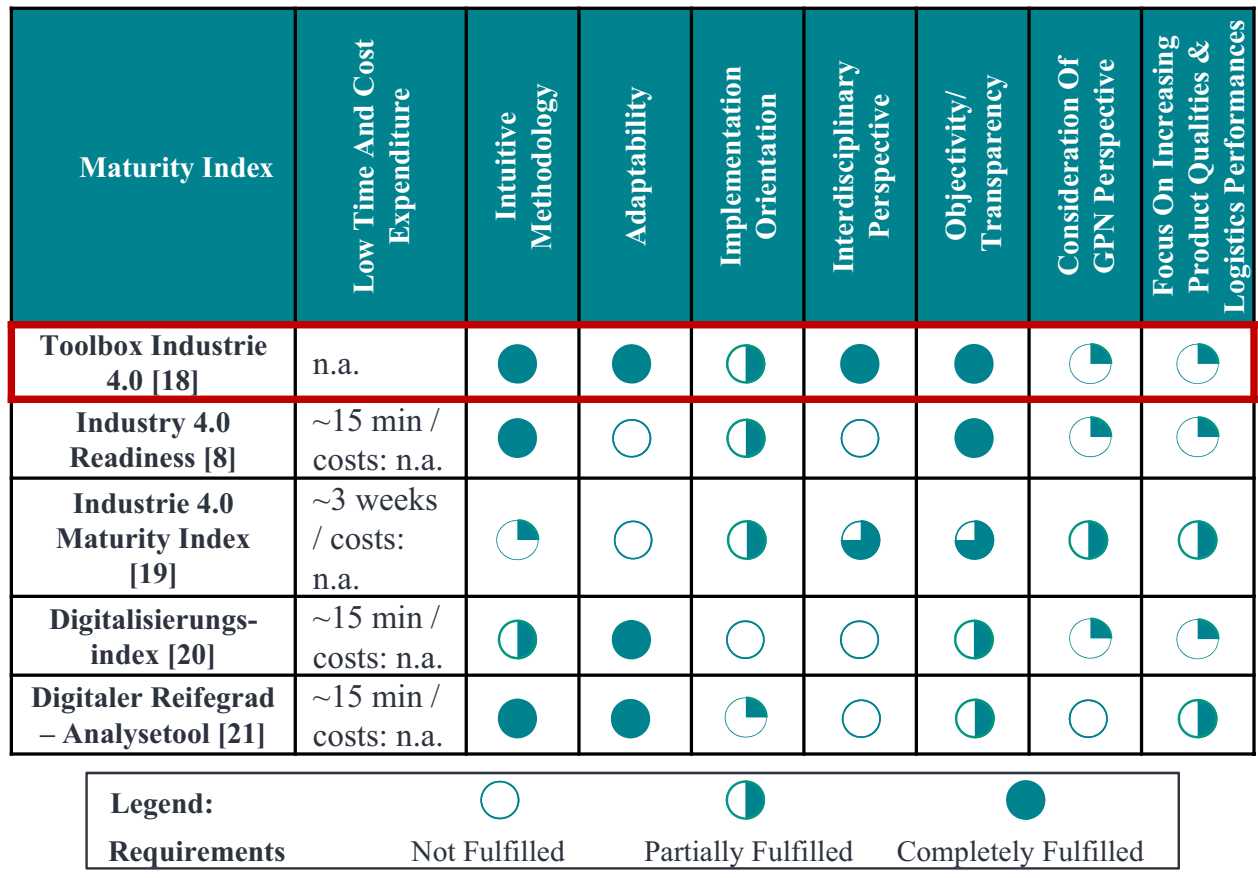

Fig. 1 Requirements for the developed process model

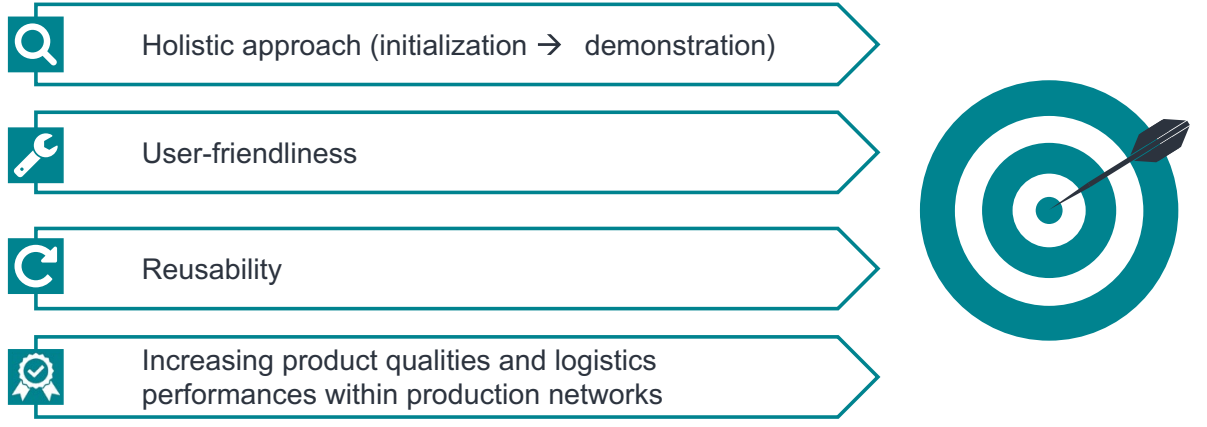

conception to realization and evaluation. Regarding the realization phase, however, it must be said that even though it is often listed as an individual phase, it is not actively supported by methods/tools. It rather includes either only references to further steps (e.g. [22]) or a mere concept elaboration (e.g. [18]).

A continuous support from the initialization phase up to the final implementation of I 4.0 use cases, especially in SMEs, is thus still pending. Consequently, a new process model explicitly allowing for the implementation of I4.0 in SMEs by means of a holistic procedure is subsequently presented. As existing models do not explicitly address increases in supplier qualities leading to more efficient GPN, the focus thereby especially lies on these aspects.

\section{Process model}

To address the deficits identified in Sect. 2 and to incorporate the requirements from Fig. 1, a chronologically structured I4.0 process model has been conceived. It is basically oriented to the process models of $[17,22]$ and extends these approaches for the application in SMEs operating in GPN. Similar to existing approaches, the model comprises five phases (initialization, analysis, conceptualization, realization, demonstration) which are depicted in Fig. 2. As a more detailed explanation in the following sections will show, the initialization phase focuses on the problem definition and project planning, while the 
Table 2 Overview of existing I4.0 process models (please note: if a certain component is not explained for a specific process model, the respective model does not consider this component) [25-31]

Process Model

Roadmap Industry 4.0 [25]

Guideline Industrie 4.0 [18]

Generisches Vorgehensmodell zur Einführung der Industrie 4.0 [26]

Metamorphose zur intelligenten und vernetzten Fabrik [27]

The Way Forward-Transforming Towards Industry 4.0 [28]

Vorgehensmodell zur Einführung von Industrie 4.0 [29]

Vorgehensmodell zur Entwicklung einer Industrie 4.0 Einführungsstrategie [30]
Components (Ph: phases; Me: methods/tools; M: milestones; D: documents)

$\mathrm{Ph}$ : analysis (kickoff, is-analysis), objective (definition of objective, definition of measures and evaluation), implementation (decision support, project definition)

Me: workshops, maturity model, SWOT analysis, creativity techniques (brainstorming, morphological analysis), method 31615, cost-benefitanalysis, balanced scorecard

$\mathrm{Ph}$ : preparation, analysis, idea generation, evaluation

Me: Workshops, maturity model, web chart for external and internal competence analysis; creativity techniques (Kano model, St. Gallen business model), BCG matrix

D: instructions on how to conduct a creativity workshop, workshop agenda, maturity model and instructions for the maturity model, example of a competence analysis and idea-finding process

$\mathrm{Ph}$ : preparation. analysis, idea generation, evaluation

Me: Workshops, maturity model, literature review, external consulting, internal exchange of knowledge; external and internal competence analysis; creativity techniques (Kata-Coaching, St. Gallen business model, Business Model Canvas); BCG matrix; prioritization methods; simulation M: Common understanding of Industry 4.0 and detection of its benefits; mapping of actual state; optimization potentials; ideas for optimization; recommendation for action; roadmap

D: maturity model

$\mathrm{Ph}$ : Internal analysis; identification of solution elements, development of a target scenario, selection of solution elements, definition of transformation strategy, implementation and evaluation

Me: workshop concept, internal analysis; creativity techniques (Business Model Canvas, St. Gallen Business Model, business model dimensions according to Schallmo), morphology for the generation of implementation strategies; multiple domain matrix

D: example procedure in the strategy workshop, instructions for the different phases, catalogue of questions for implementation planning, success factors for five categories (data, production system, internal/ overlapping value creation and services and products)

$\mathrm{Ph}$ : digital maturity analysis, identification of opportunities and risks; defining an Industry 4.0 vision; and agenda, prioritization of areas for transformation, Industry 4.0 roadmap

$\mathrm{Ph}$ : initiative (goals and problems), I 4.0 assessment (degree of maturity and potentials), method specification; risk-potential analysis, implementation

Me: workshop concept; maturity model; method toolbox; risk and potential analysis

M: field of action, list of preselected methods, decision basis, incremental launch strategy

D: Toolbox of I 4.0 methods/measures

$\mathrm{Ph}$ : analysis of actual Industry 4.0 situation, target determination, implementation of measures

Me: 3C model; positioning matrix (y-axis: experience with Industry 4.0, $\mathrm{x}$-axis: need to adapt business strategy)

D: template for 3C model analysis; template for analysis of the degree of experience with

Industry 4.0 approaches and technologies 
Table 2 (continued)

Process Model

Components (Ph: phases; Me: methods/tools; M: milestones; D: documents)

Industrie 4.0

Readiness: Migration zur Industrie 4.0-Fertigung [22]

Roadmap Industrie 4.0 [31]
$\mathrm{Ph}$ : process analysis, Industry 4.0 assessment, implementation planning Me: workshop concept, value stream analysis, expert survey, gap analysis, benchmarking, Industry 4.0 toolbox (incl. standard application cases and implementation examples)

M: awareness, cognition, commitment, long and short list of use cases; project program, commitment of staff, evaluated use cases, implementation experience, implementation roadmap for Industry 4.0, evaluated and new use cases, Industry 4.0 production system

$\mathrm{Ph}$ : assessment; identification, selection and rating of potentials; creation of roadmap

Me: Workshop concept; quick check 4.0 incl. SWOT analysis, PESTEL analysis, business model canvas and other creativity techniques (brainstorming, mind mapping, morphology), Potentialfinder 4.0 incl. I4.0 layer model, evaluation catalogue, potential matrix; enabler 4.0 (overview of necessary prerequisites for the implementation of Industry 4.0-potentials), evaluation methods (investment calculation, extended performance analysis), roadmapping

D: templates for the business model Canvas, the PESTEL analysis, the SWOT analysis, the I4.0-layer model, the evaluation catalogue, the potential matrix, the Enabler 4.0, an investment calculation, the extended performance analysis and for roadmapping
Fig. 2 Process model for the development, implementation and demonstration of I4.0 showcases for SMEs in GPN

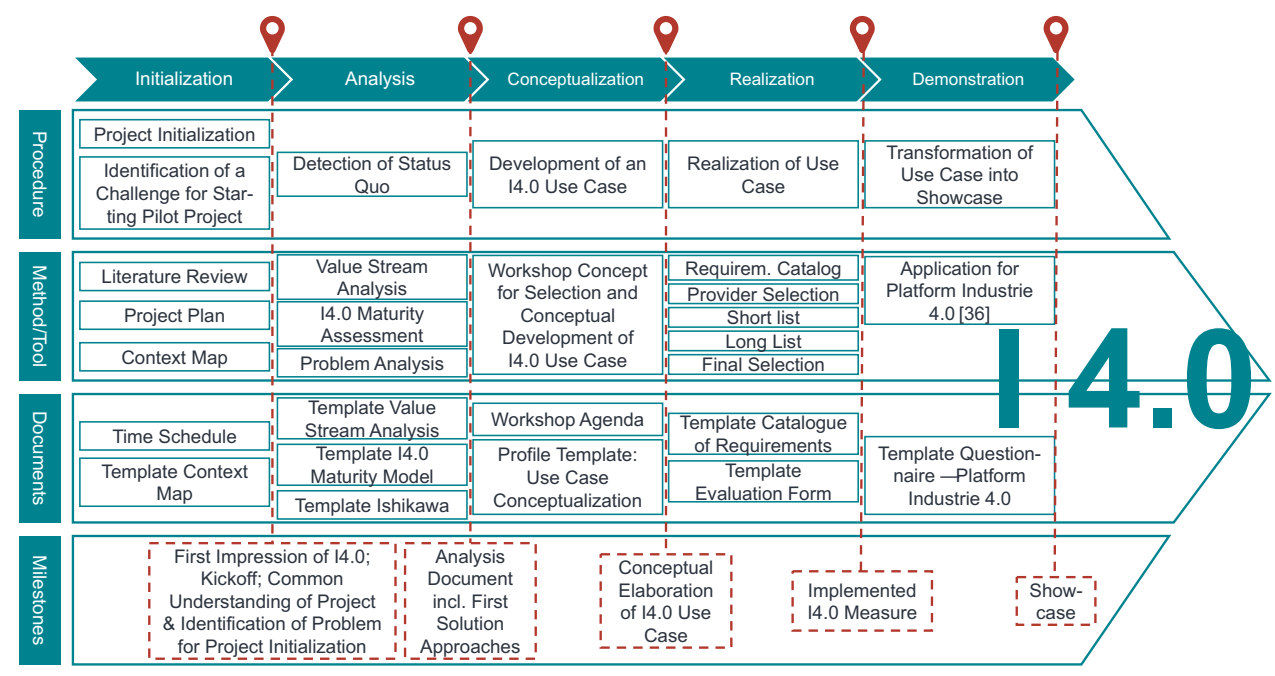

analysis phase records the status quo and reveals potentials for improvement. The conceptualization phase, moreover, aims at developing an I4.0 solution for the identified problem, which is then implemented in the realization phase. Within the demonstration phase, finally, the solution is transformed into a showcase which can serve as an inspiration for other companies on their way towards I4.0. For guaranteeing user-friendliness and comprehensibility, all of these phases are supported by dedicated methods, documents and milestones (Fig. 2) [23].

\subsection{Initialization}

The process model thereby starts with the initialization phase (Fig. 2). Apart from a careful preparation that aims at avoiding risks, this phase also includes project planning [24]. This entails the definition of a higher-level project plan and time schedule [23]. Here, all executive and management personnel from areas such as IT, logistics, production and quality have to be involved. Once the project team is fixed, its members are asked to develop an initial knowledge on I4.0 (e.g. by a literature review). This serves as a basis for a precise problem definition during the kickoff meeting where a precise field of action is agreed upon within which the 
derived I4.0 solution can contribute to improved product qualities or logistics performances. Such a field of action might be the lack of traceability of WIP or parts which leads to delayed deliveries and hence low customer satisfaction rates.

\subsection{Analysis}

Thereafter, the status quo of the identified field of action has to be thoroughly recorded in order to elaborate core potentials and weaknesses and to develop initial solution approaches. For a structured recording of the status quo, the developed approach proposes two methods that support the project team in observing the field of action: The value stream analysis, on the one hand, examines affected GPN processes [32] to identify potentials for improvement in terms of process control (e.g. superfluous process steps). Since the classical value stream analysis is usually limited to a door-to-door-modelling for a single plant [33], further symbols (e.g. for manual and automatic processes, scrap, small load carriers as well as for internal and external material flows) were added to conduct a network-based analysis.

The Industry 4.0 Maturity Model, on the other hand, supports the assessment of the actual state and helps to unveil potentials that might address weaknesses discovered during the value stream analysis with an I4.0 focus. As mentioned before, the toolbox developed by [18] serves as a basis. To meet the requirements of a cross-company assessment, however, it has been adapted and complemented by the GPN perspective. Therefore, the model differentiates between the "supplier" perspective which separately evaluates all suppliers within a GPN and the "GPN" perspective that analyses the I4.0 maturity levels of the network as a whole. Since the focus of the paper lies on improving supplier quality in terms of their processes without explicitly addressing the improvement of products in terms of usability and customer value, the supplier perspective does not differentiate between the production and the product dimension proposed by [18]. Instead, aspects such as the machine-machine-communication are adopted from [18] and particularly supplemented by aspects such as the avoidance of errors, hence explicitly allowing for a comprehensive overview of the supplier quality in terms of their production processes. The obtained model is shown in Figs. 3 and 4.

After the weaknesses in the field of action have been elaborated by means of the value stream analysis, they have to be analyzed and subdivided into their original root causes. Therefore, the problem analysis (e.g. Ishikawa) offers a structured approach. Based on that, the I4.0 maturity assessment might unveil potentials how certain root causes might be eliminated or reduced by means of a stronger focus on
I4.0. The maturity assessment therefore serves for identifying potential initial solution approaches.

\subsection{Conceptualization}

Based on the analysis phase, the conception phase aims at developing a concept for an I4.0 use case which paves the way to solve the selected problem according to its root causes. Therefore, a structured one-day workshop is suggested in which I4.0 ideas are generated, prioritized and conceptualized. The workshop concept is divided into four major agenda points:

1. I4.0 keynote: The keynote motivates the workshop participants and provides incentives for an increased I4.0 implementation. Besides, by repeating the acquired knowledge on I4.0, it ensures a common understanding for all participants.

2. Presentation of results on value stream analysis, maturity assessment and problem analysis: During this agenda point, the results from the value stream analysis, the I4.0 assessment and the problem analysis are presented and further serve as a basis for the creativity part.

3. Creativity part: The creativity part consists of four steps, which are carried out using the metaplan technique. This way, all workshop participants make a contribution and more ideas might be uncovered [34]. As shown in Fig. 5, the first step of the creativity part comprises an individual working part aiming at the generation and transcription of ideas for solving the selected problem by means of I4.0 according to the respective root causes. After having written the ideas down, all participants present their proposals to the remaining participants. Based on this, ideas are clustered to measures on a metaplan board and then discussed and analyzed by the whole team. Finally, the measures are prioritized using evaluation points which are pinned to the favorite measures on the board. The measure with the highest priority (highlighted in red in Fig. 5) is then conceptually developed into a use case.

4. Conceptual development of the use case: The conceptual elaboration of the use case forms the central part of the workshop. It aims at further developing the measure into a use case concept (e.g. holistic traceability solution to track WIP and parts in progress). For supporting the development of the conceptual design, the project team is provided with a template which can be understood as a concise project profile (see Fig. 6). It contains the most important facts and serves both as a documentation of the conception phase and as an information basis for the realization phase. The template is divided into three levels and ranges from idea and realization to evaluation. On the idea level, the as-is situation and the target state 
Fig. 3 Adapted I4.0 maturity model [dimension "supplier" (building upon [18])]
Base

Advanced

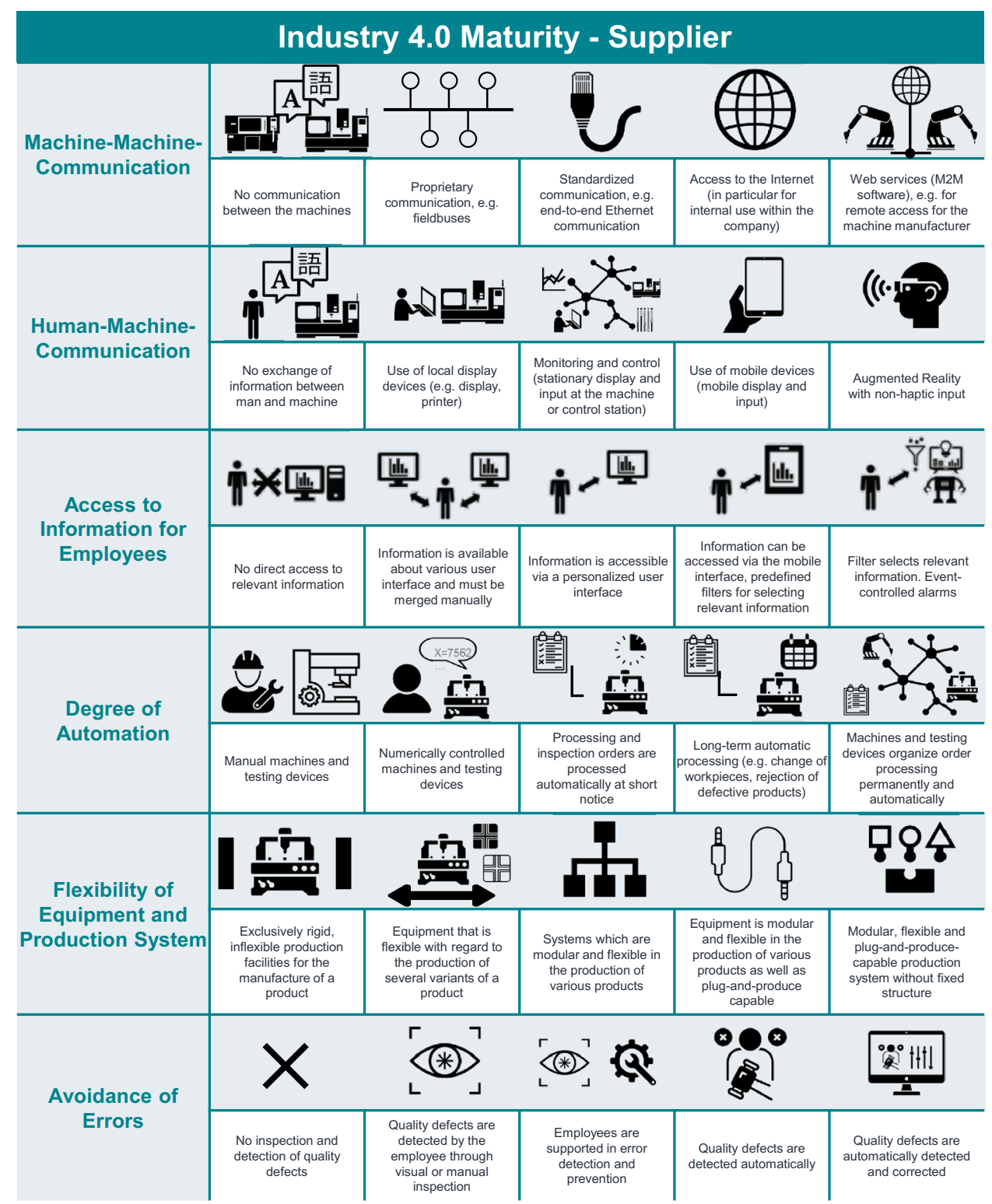

of the use case are recorded. Besides, it is described how the target state shall be achieved. The realization level ensures that the concept can be carried out in a targeted manner. Therefore, necessary prerequisites and requirements must be recorded. Subsequently, both the milestones of the use case and the responsible persons as well as the planned project duration are captured. On the evaluation level, possible opportunities and risks can be noted. Moreover, an initial cost estimation or limit can be recorded.

\subsection{Realization}

Since the majority of SMEs wishing to implement I4.0 solutions on their shopfloors depends on externally purchased technology or know-how [35], the realization phase is designed for the assumption that a new machine, technology or IT system has to be purchased to implement the use case concept. In this context, the model offers assistance in order to be able to carry out the specification and selection process in a structured manner. Accordingly, the procedure 
Fig. 4 Adapted I4.0 maturity model [dimension "GPN" (building upon [18])]

Base

Advanced

\begin{tabular}{|c|c|c|c|c|c|}
\hline & 1 & stry & aturity - & $\mathbf{N}$ & \\
\hline $\begin{array}{c}\text { Interaction } \\
\text { between }\end{array}$ & & & & & \\
\hline $\begin{array}{l}\text { Quality and } \\
\text { Logistics }\end{array}$ & $\begin{array}{l}\text { Different production, } \\
\text { quality and logistics } \\
\text { systems and manual } \\
\text { data exchange }\end{array}$ & $\begin{array}{l}\text { Automatic data } \\
\text { exchange between } \\
\text { systems at regular } \\
\text { intervals }\end{array}$ & $\begin{array}{l}\text { Shared or fully } \\
\text { integrated production, } \\
\text { quality and logistics } \\
\text { systems }\end{array}$ & $\begin{array}{l}\text { Common systems with } \\
\text { real-time information } \\
\text { and warnings in case } \\
\text { of malfunctions / } \\
\text { errors }\end{array}$ & $\begin{array}{l}\text { Common systems that } \\
\text { automatically respond } \\
\text { and adjust in real-time }\end{array}$ \\
\hline Tracing & No traceability & $\begin{array}{l}\text { Traceability with read } \\
\text { operation for easy } \\
\text { information } \\
\text { (e.g. product ID) }\end{array}$ & \begin{tabular}{|c} 
Traceability with reading \\
and writing process for \\
simple information (e.g. \\
product ID)
\end{tabular} & $\begin{array}{l}\text { Traceability with read and } \\
\text { write operation for complex } \\
\text { information (e.g. product } \\
\text { ID, time stamp, } \\
\text { parameters) }\end{array}$ & $\begin{array}{l}\text { Reading and writing of } \\
\text { complex information as an } \\
\text { integral functional } \\
\text { component of the product }\end{array}$ \\
\hline Tracking & $\begin{array}{l}\text { No tracking of parts } \\
\text { along the supply chain }\end{array}$ & $\begin{array}{l}\text { Tracking of parts in the } \\
\text { network at predefined } \\
\text { identification points }\end{array}$ & $\begin{array}{c}\text { Tracking of parts at } \\
\text { predefined points and } \\
\text { event-based information } \\
\text { processing }\end{array}$ & $\begin{array}{l}\text { Continuous tracking with } \\
\text { event-based ifformation } \\
\text { processing }\end{array}$ & $\begin{array}{l}\text { Continuous tracking and } \\
\text { autonomousus real-time } \\
\text { interaction with other } \\
\text { planning systems }\end{array}$ \\
\hline Use of & & & & $\mathrm{II}^{3}$ & 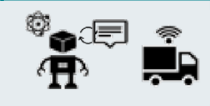 \\
\hline Load Carriers & $\begin{array}{l}\text { Product and supplier- } \\
\text { specific load carriers with } \\
\text { repackaging and lack of } \\
\text { uniform labelling }\end{array}$ & $\begin{array}{l}\text { Product and supplier- } \\
\text { specific load carriers with } \\
\text { repackaging, but uniform } \\
\text { labelling }\end{array}$ & $\begin{array}{l}\text { Product-specific, but } \\
\text { jointly used load carriers } \\
\text { with uniform labelling }\end{array}$ & $\begin{array}{l}\text { Product and supplier } \\
\text { overlapping load carriers } \\
\text { with uniform labelling }\end{array}$ & $\begin{array}{l}\text { Uniform, standardized } \\
\text { and intelligent load } \\
\text { carriers with extended } \\
\text { functions }\end{array}$ \\
\hline & & & & $=$ & (ऐ) \\
\hline $\begin{array}{l}\text { Planning } \\
\text { Information }\end{array}$ & $\begin{array}{l}\text { No data exchange within } \\
\text { the GPN }\end{array}$ & $\begin{array}{l}\text { Manual exchange of data } \\
\text { by e-mail or telephone on } \\
\text { request }\end{array}$ & $\begin{array}{l}\text { Data exchange within the } \\
\text { GPN via Internet-based } \\
\text { portals with previously } \\
\text { entered data }\end{array}$ & $\begin{array}{l}\text { Automatic, event-driven, } \\
\text { reciprocal exchange of } \\
\text { data within the GPN }\end{array}$ & $\begin{array}{l}\text { Fully integrated systems } \\
\text { support close interaction } \\
\text { between network } \\
\text { partners and integrate } \\
\text { their business processes }\end{array}$ \\
\hline Collaboration & (c) & $\begin{array}{l}\text { (6) } \\
69.9\end{array}$ & 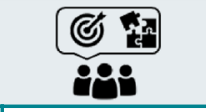 & 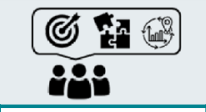 & 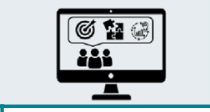 \\
\hline $\begin{array}{l}\text { and the Will to } \\
\text { Solve Problem }\end{array}$ & $\begin{array}{l}\text { Partners pursue their } \\
\text { own goals. Problems are } \\
\text { solved reactively and in } \\
\text { isolation. } \\
\text { No best practice transfer }\end{array}$ & $\begin{array}{l}\text { Common goals are } \\
\text { pursued. Problems are } \\
\text { solved reactively and in } \\
\text { isolation. No best } \\
\text { practice transfer }\end{array}$ & $\begin{array}{c}\text { Common goals. } \\
\text { Problems are solved } \\
\text { jointly but reactively. } \\
\text { No best practice transfer }\end{array}$ & $\begin{array}{l}\text { Common goals and } \\
\text { proactive bilateral } \\
\text { continuous improvement } \\
\text { to solve problems within } \\
\text { the GPN }\end{array}$ & $\begin{array}{l}\text { Common goals, fully } \\
\text { integrated system-- } \\
\text { supported continuous } \\
\text { improvement. Intensive } \\
\text { exchange and best } \\
\text { practice transfer }\end{array}$ \\
\hline
\end{tabular}

Fig. 5 Four step procedure of the creativity part

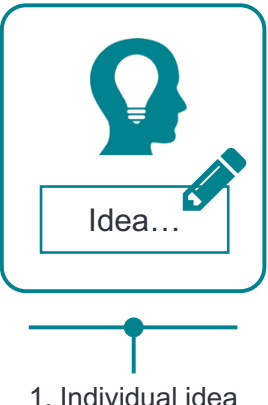

1. Individual idea generation

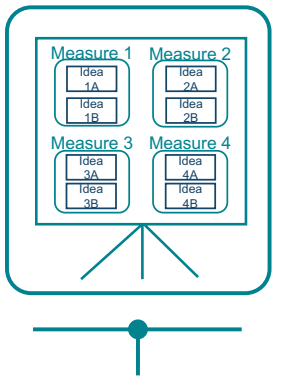

2. Clustering of ideas to measures

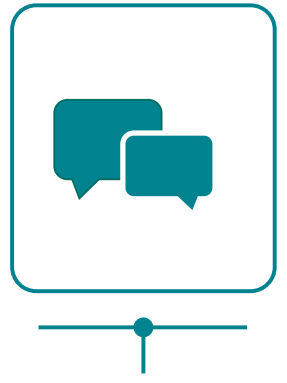

3. Discussion of measures

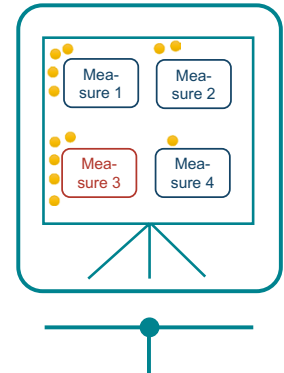

4. Prioritization of measures 
Fig. 6 Project profile for use case conceptualization

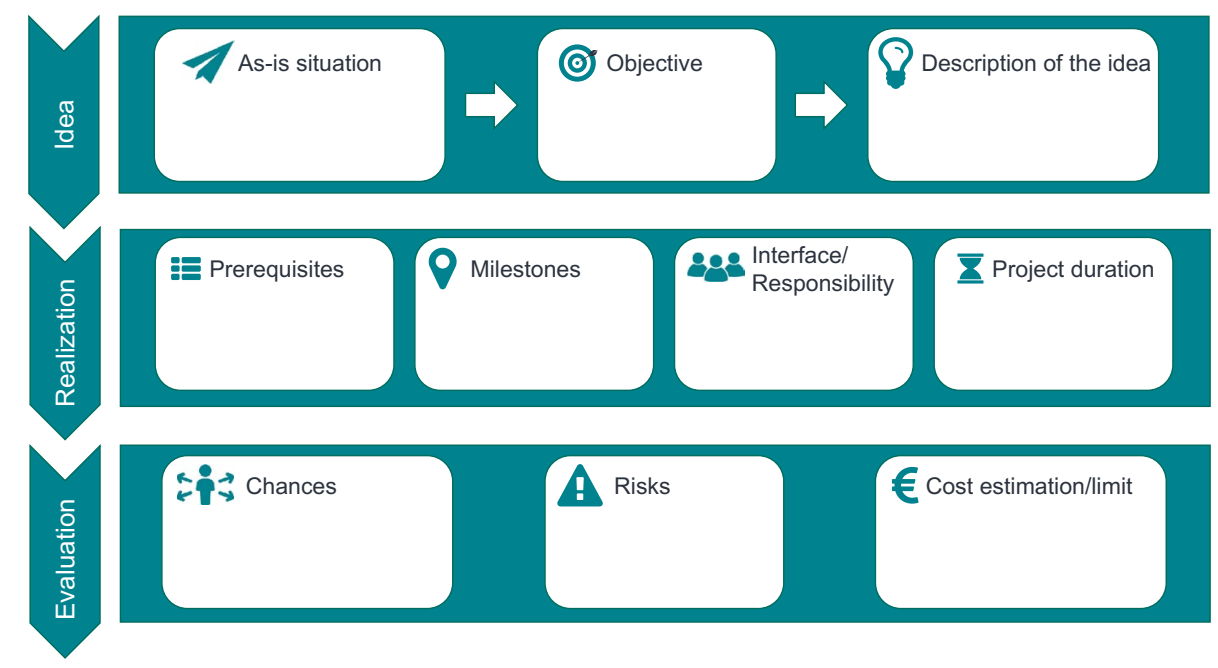

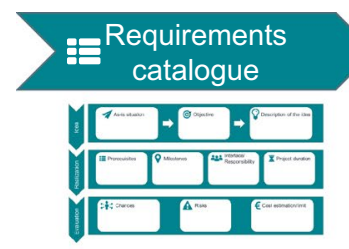

Project profile

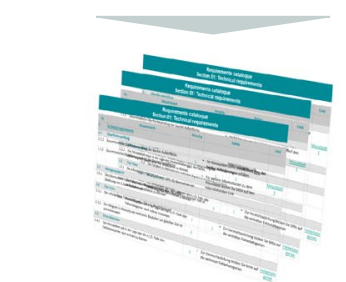

Requirements catalogue including technical, infra-structural, or system requirements

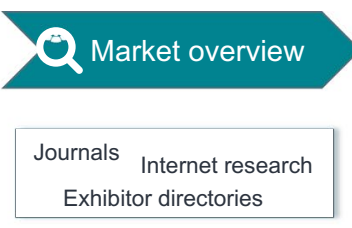

Screening

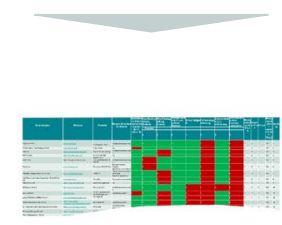

Market overview (longlist)
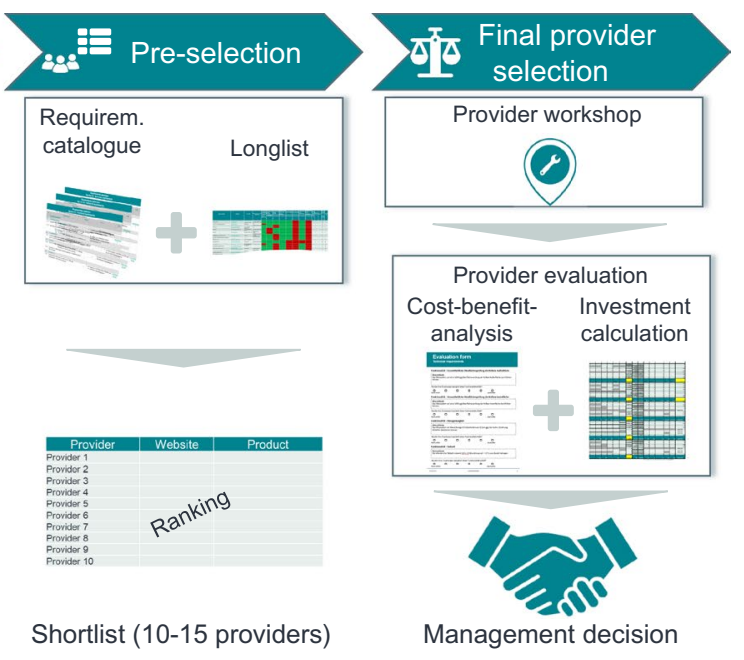

Shortlist (10-15 providers)

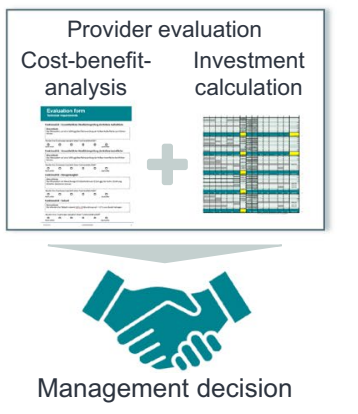

Management decision

Fig. 7 Four step procedure for the realization phase

is subdivided into the four steps "requirements catalogue", "market overview (longlist)", "pre-selection (shortlist)", and "final provider selection" shown in Fig. 7.

As Fig. 7 indicates, the creation of a requirements catalogue is the essential first step, which aims at transferring the requirements from the project profile (Fig. 6) into concrete requirements including their importance or prioritization. In addition to general requirements, the catalogue can, especially for technical use cases (such as the introduction of RFID tags within the GPN), also contain technical requirements, infrastructural requirements or system requirements. Based on the catalogue, as many providers as possible are identified who might be considered for the desired solution. Therefore, a rough screening has first of all to be conducted which results in a market overview (longlist). Exhibitor directories of relevant industrial fairs or internet research might thereby serve as adequate means. After the compilation of all potential providers, the longlist might have a considerable scope, which should be reduced to $10-15$ providers (shortlist) by means of a pre-selection. For this purpose, the catalogue of requirements can be used to successively compare the information published on the provider websites with the determined requirements. According to their respective degrees of requirements' fulfillment, the providers are then put into a lexicographical ranking and the ones with the highest ranking are included in the shortlist. Aiming at a final provider selection, these providers are then contacted with the requirements catalogue and asked for a statement regarding the requirements. The two to four providers whose feedback appears most promising with regard to the fulfilment of the requirements are then invited to a 
provider workshop. The workshop thereby aims at getting to know the remaining providers and their solution concepts in detail. In this context, it is important to pre-define the objectives of the workshop in order to be able to evaluate solutions, appearances and knowledge of the providers as accurately as possible. The subsequent evaluation of the providers should thereby include non-monetary as well as monetary aspects: Non-monetary aspects will, on the one hand, be compared by means of a cost-benefit analysis. The investment calculation, on the other hand, will reflect monetary aspects. Both results are finally consulted by the management for making a decision. Afterwards, the provider has to draw up a functional specification according to which the purchase contract is finalized. With the final implementation of the I4.0 measure, the realization phase is considered to be successfully completed.

\subsection{Demonstration}

Building upon the realization phase, the demonstration phase aims for transforming the realized I4.0 application into an I4.0 showcase that serves as an inspiration for other enterprises to enhance I4.0 penetration in SMEs in GPN by simultaneously promoting the innovation performance of the company. For reaching this, the present model refers to a questionnaire proposed by the VDMA, which can be seen as an application document and as an instrument of assistance for transforming the I4.0 use case into a showcase for the Platform Industrie 4.0-an extensive and valuable collection of practice-oriented I4.0 applications [36]. Since the platform is used as a popular source of information by institutions and companies alike, both its multiplication effects as well as its use as a source of information for companies are good reasons to promote the showcases on the platform [23].

\section{Application to industrial use case}

After having introduced the process model from a theoretical point of view, its steps are subsequently applied to the GPN of a globally acting first-tier system supplier to the automotive industry. So as to provide incentives to improve product quality and logistics performance within the GPN despite high complexities, the company has initiated a project to define and implement supplier-specific I 4.0 showcases based on the presented procedure. These showcases are intended to serve as lighthouse projects for improving supplier qualities and logistics performances within the GPN by means of I4.0. The overriding, longterm objective thereby lays in avoiding customer complaints and in increasing customer satisfaction.

For identifying potential problems, a kickoff workshop was held during the initialization phase to brainstorm potential suppliers of the first-tier supplier, for which a targeted I4.0 solution could contribute to an improvement in supplier quality. Based on the number of past customer complaints, three promising supplier use cases have been identified. One of the three supplier-specific I4.0 use cases will subsequently be examined in more detail.

Generally, the supplier is a manufacturer of technical moldings made of thermo- and duroplastic materials, who serves companies in the automotive, electrical as well as medical technology industries and therefore employs a low three-digit workforce. The particular topic that has been selected is the supply of duroplastic pistons with quality defects (e.g. scratches, break-outs), which despite a

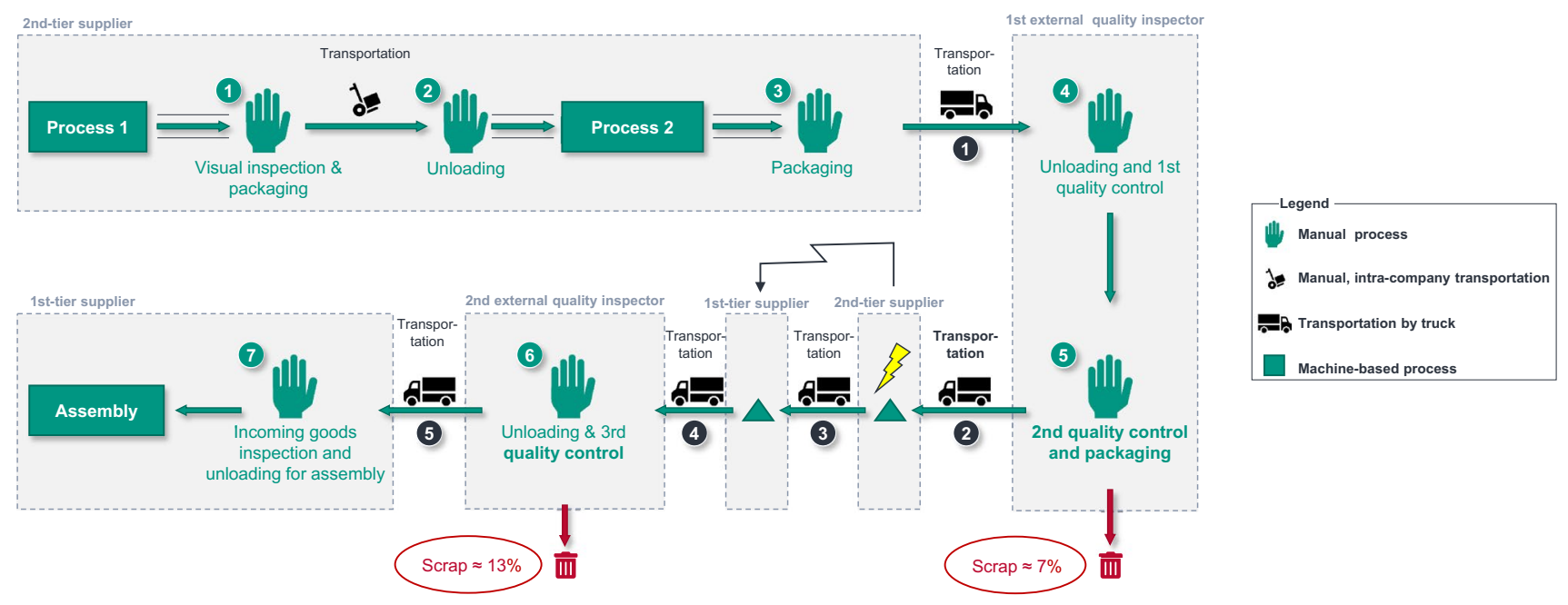

Fig. 8 Value stream analysis for the use case 

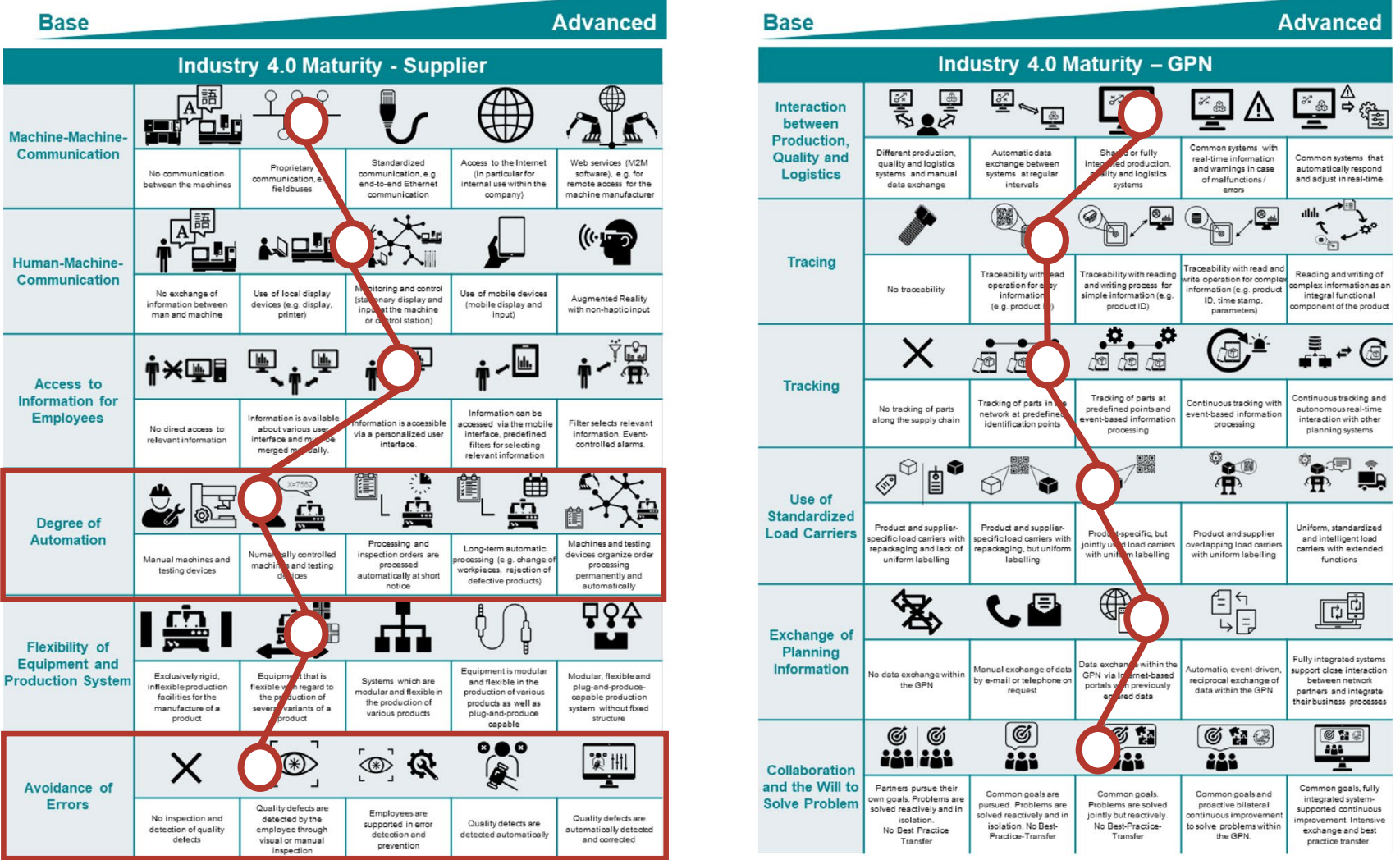

Particularly relevant directions for improvement related with the high amount of defective pistons and the high number of manual process steps

Fig. 9 I4.0 maturity assessment for the use case

preceding threefold manual visual inspection led to complaints from the first-tier supplier's customer. Hence, the overall objective of the use case was to guarantee a $100 \%$ delivery of pistons without quality defects from the second- to the first-tier supplier. Thus, a network-based value stream analysis was first of all carried out (Fig. 8) in order to reveal critical process steps (analysis phase).

Besides, the I4.0 maturity assessment, both from the network as well as from the supplier perspective, was applied to investigate which of the supplier's fields of action might benefit from an increased I4.0 implementation. To guarantee pistons without quality defects, Fig. 9 shows that the I4.0 maturity assessment particularly revealed two promising directions for development: "degree of automation" and "avoidance of errors" (see Figs. 3, 4).

The results obtained from these two examinations were brought together within the scope of a problem analysis which also already proposes potential solution approaches. As Fig. 10 unveils, several root causes and a potential solution approach for the reduction of the amount of defective pistons could be identified: In addition to the production layout and the variety of manual movements, impure environmental conditions or the time-consuming threefold visual inspection might exemplarily be named as root causes for the high scrap rate. Potential solution approaches for ensuring a high piston quality and hence for avoiding the delivery of pistons with quality defects might, on the one hand, include the application of basic lean principles (upper part in Fig. 10). On the other hand, they might refer to the use of more sophisticated I4.0 technologies which are related to the I4.0 maturity assessment and include the avoidance of errors and the reduction of manual process steps (lower part in Fig. 10).

For subsequently elaborating concrete solution approaches in the conceptualization phase, 22 ideas were generated using the four step procedure of the creativity part (see Sect. 3.3). These 22 ideas were then assigned to one of the following five clusters: "optical \& automated quality assurance", "material flow", "clean room", "tool monitoring", and "packaging \& traceability". Discussing and prioritizing these clusters finally led to the decision that the measure "optical \& automated quality assurance" should be elaborated in more detail. Therefore, by means of the methodology presented in Sect. 3.4, a project profile was detailed, 


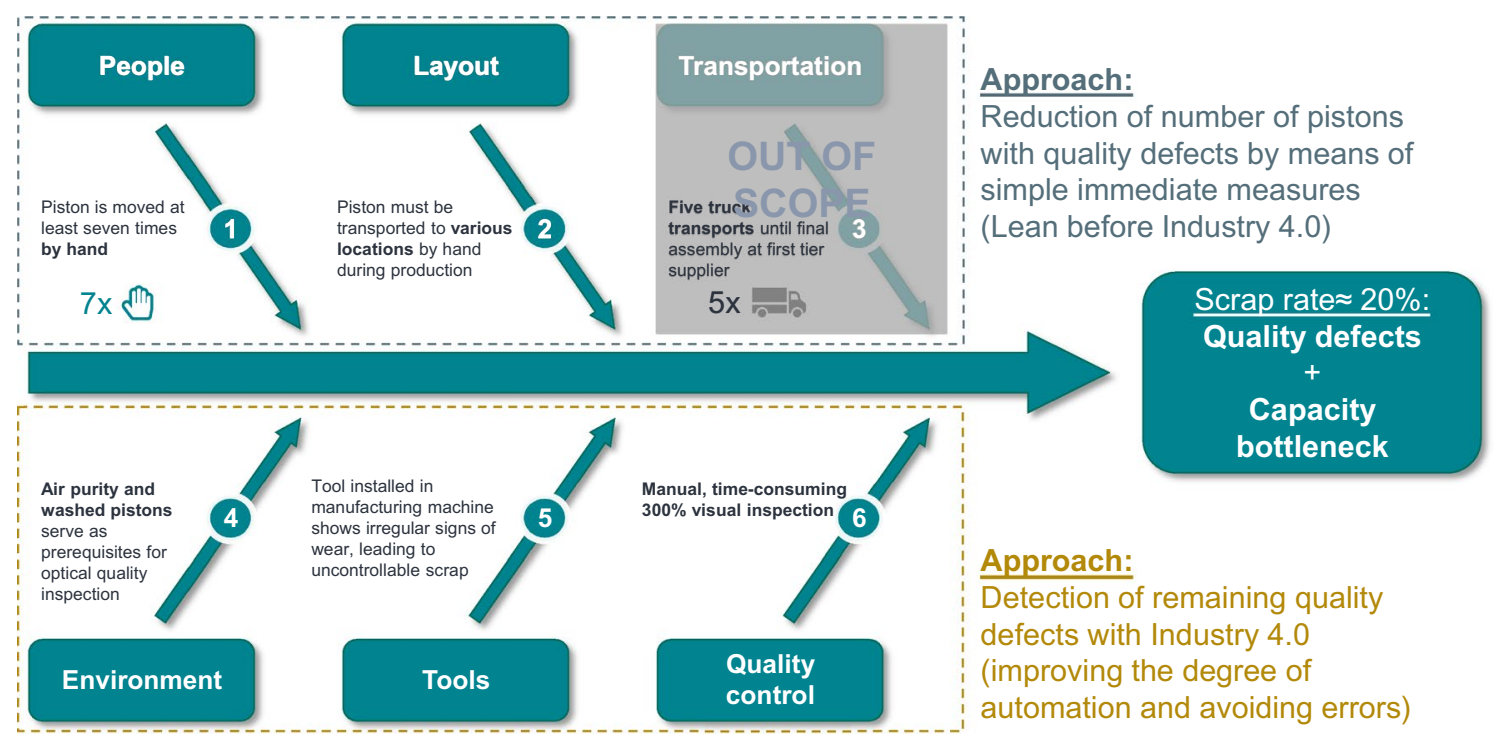

Fig. 10 Problem analysis

Fig. 11 Cost-benefit analysissection "requirements"

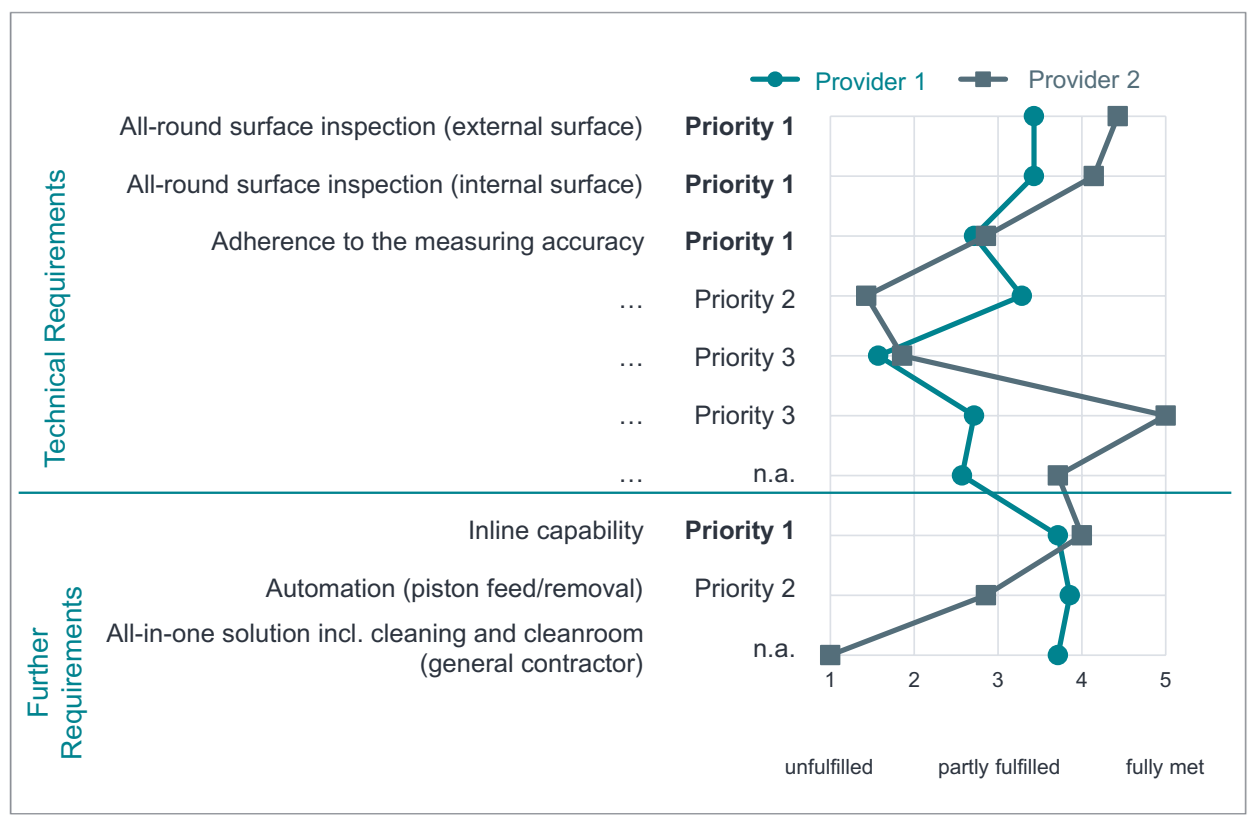

which served as the starting point for the realization phase and thus for the search for and selection of potential solution providers.

The "implementation of a quality control system for an automatic inspection of the outer and inner surfaces of the piston, allowing for an assessment of the pistons in terms of their status (defective; non-defective) and thus for the prevention of the supplier from delivering defective parts to the first-tier supplier" has thereby been defined as the concrete objective of the use case. With respect to important requirements that have to be taken into account, the adherence to the measuring accuracy, the necessity for a $100 \%$ fault detection for inner and outer surfaces and the provision of an all-in-one solution were worked out (also see Fig. 11). These requirements have, among others, been included in the requirements catalogue in order to allow potential providers to get an idea of the task.

When searching for suitable technology providers, the provider directories of relevant trade fairs for quality assurance were first screened, resulting in 106 possible providers (longlist). After an intensive examination of their websites, a shortlist of the ten most suitable providers could be drawn 
up. These were contacted with the requirements catalogue, requesting a statement on the task. While six of the ten providers reported that they were not qualified for the task, the four remaining ones expressed general interest. Hence, sample parts were exchanged with these four providers for carrying out test measurements. However, only two providers yielded promising results with their respective solutions, so that they were invited to the selection workshop and subsequently evaluated regarding their suitability by means of a cost-benefit analysis (see excerpt in Fig. 11).

As Fig. 11 reveals, none of the providers convinced unrestrictedly compared to its competitor. However, as only "Provider 1" showed willingness to act as general contractor, the decision was ultimately made in its favor. Currently, his proposed, camera-based solution is implemented, whereupon the use case will be displayed as a showcase on the Platform Industry 4.0 as part of the demonstration phase.

\section{Conclusion}

Arisen from an increased need for a holistic methodological support of SMEs in implementing I4.0, this paper proposes a process model for the realization and demonstration of SME-based I4.0 showcases in GPN. The methodology is subdivided into five phases and focuses on increasing product qualities and logistics performances within GPN. Unique selling points of the model include a holistic and continuous methodological support, especially in the realization phase, and the network-wide alignment. This way, the model supports GPN-wide improvements which result from an increased I4.0 implementation at SMEs. The method was successfully applied to the GPN of a first-tier supplier to the automotive industry and its suitability for developing specific I4.0 use cases could be proven by implementing a camera-based quality assurance system which replaces costly manual optical inspection and ensures a $100 \%$ delivery of non-defective pistons from the small-sized second-tier supplier to the first-tier supplier.

\footnotetext{
Acknowledgements Open Access funding provided by Projekt DEAL. The authors would extend their thanks to the German Research Foundation (DFG) for supporting the research project "Migration planning of global production networks" (LA-2351/45-1).
}

Open Access This article is licensed under a Creative Commons Attribution 4.0 International License, which permits use, sharing, adaptation, distribution and reproduction in any medium or format, as long as you give appropriate credit to the original author(s) and the source, provide a link to the Creative Commons licence, and indicate if changes were made. The images or other third party material in this article are included in the article's Creative Commons licence, unless indicated otherwise in a credit line to the material. If material is not included in the article's Creative Commons licence and your intended use is not permitted by statutory regulation or exceeds the permitted use, you will need to obtain permission directly from the copyright holder. To view a copy of this licence, visit http://creativecommons.org/licenses/by/4.0/.

\section{References}

1. Lanza G, Stoll J, Stricker N et al (2013) Measuring global production effectiveness. Proc CIRP 7:31-36. https://doi.org/10.1016/j. procir.2013.05.006

2. El Maraghy H, Schuh G, El Maraghy W et al (2013) Product variety management. CIRP Ann 62(2):629-652. https://doi. org/10.1016/j.cirp.2013.05.007

3. MacDougall W (2018) Industrie 4.0 Germany market report and outlook. Germany Trade \& Invest, Berlin. https://www.gtai.de/ resource/blob/64500/8b7afcaa0cce1ebd42b178b4430edc82/indus trie4-0-germany-market-outlook-progress-report-en-data.pdf. Accessed 29 Jan 2020

4. Rüßmann M, Lorenz M, Gerbert $P$ et al (2015) Industry 4.0: the future of productivity and growth in manufacturing industries. Boston Consult Group 9(1):54-89

5. Moeuf A, Pellerin R, Lamouri S et al (2018) The industrial management of SMEs in the era of Industry 4.0. Int J Prod Res 56(3):1118-1136. https://doi.org/10.1080/00207543.2017.13726 47

6. Federal Ministry for Economic Affairs and Energy (2018) The German Mittelstand as a model for success. https://www.bmwi.de/ Redaktion/EN/Dossier/sme-policy.html. Accessed 25 Sept 2019

7. Schröder C (2017) The challenges of Industry 4.0 for small and medium-sized enterprises. Friedrich-Ebert-Stiftung, Bonn

8. Lichtblau K, Stich V, Bertenrath R, Blum M, Bleider M, Millack A, Schmitt K, Schmitz E (2015) Industry 4.0 readiness. http://www.impuls-stiftung.de/documents/3581372/4875823/ Industrie\%304.0\%30Readiness\%30IMPULS\%30Studie\%30Okt ober\%302015_eng.pdf/476b43ea-7181-4c47-9c56-f37d32e718 17. Accessed 26 Sept 2019

9. Xu LD, Xu EL, Li L (2018) Industry 4.0: state of the art and future trends. Int J Prod Res 56(8):2941-2962. https://doi. org/10.1080/00207543.2018.1444806

10. Bundesministerium für Wirtschaft und Energie (2016) Fortschreibung der Anwendungsszenarien der Plattform Industrie 4.0. https://www.plattform-i40.de/PI40/Redaktion/DE/Downl oads/Publikation/fortschreibung-anwendungsszenarien.pdf? blob=publicationFile \&v=6. Accessed 05 July 2019

11. Lanza G, Ferdows K, Kara S et al (2019) Global production networks: design and operation. CIRP Ann Manuf Technol 68(2):823-841

12. Vaidya S, Ambad P, Bhosle S (2018) Industry 4.0-a glimpse. Proc Manuf 20:233-238. https://doi.org/10.1016/j.promf g.2018.02.034

13. Aguilar-Savén RS (2004) Business process modelling: review and framework. Int J Prod Econ 90(2):129-149. https://doi. org/10.1016/S0925-5273(03)00102-6

14. Becker J, Knackstedt R, Pöppelbuß J (2009) Developing maturity models for IT management. Bus Inf Syst Eng 1(3):213-222. https ://doi.org/10.1007/s12599-009-0044-5

15. Weckenmann A, Akkasoglu G (2011) Maturity method for the development of metal forming processes considering fuzzy input parameters. In: Proceedings of the 6th international conference and exhibition on design and production of machines and dies/ molds (DIEMOLD), pp 9-15

16. Häberer S, Lau L, Behrendt F (2017) Development of an Industrie 4.0 maturity index for small and medium-sized enterprises. In: Proceedings on the 7th IESM conference, vol 7, pp 129-134 
17. Noehring F, Woestmann R, Wienzek T et al (2019) Socio-technical capability assessment to support implementation of cyberphysical production systems in line with people and organization. In: Nunes IL (ed) Advances in human factors and systems interaction: proceedings of the AHFE 2018 international conference on human factors and systems interaction, July 21-25, 2018, Loews Sapphire Falls Resort at Universal Studios, Orlando, vol 781. Springer, Cham, pp 299-311

18. Anderl R, Picard A, Wang Y et al (2016) Guideline Industrie 4.0: guiding principles for the implementation of Industrie 4.0 in small and medium sized businesses. In: VDMA Forum Industrie, vol 4, pp 1-31

19. Schuh G, Anderl R, Gausemeier J et al (eds) (2017) Industrie 4.0 maturity index: managing the digital transformation of companies (acatech STUDY). acatech STUDY. Herbert Utz Verlag, München

20. Deutsche Telekom AG (2017) Digitalisierungsindex. https://www. digitalisierungsindex.de. Accessed 16 Sept 2018

21. Hochschule Neu-Ulm (HNU) \& minnosphere (2017) Digitaler Reifegrad-Analysetool. http://reifegradanalyse.hs-neu-ulm.de/ questions.php\#firstPage. Accessed 28 May 2019

22. Bildstein A, Seidelmann J (2014) Industrie 4.0-readiness: migration zur Industrie 4.0-fertigung. In: Bauernhansl T, Hompel M ten, Vogel-Heuser B (eds) Industrie 4.0 in produktion, automatisierung und logistik. Springer Fachmedien Wiesbaden, Wiesbaden, pp 581-597

23. Federal Ministry for Economic Affairs and Energy, Federal Ministry of Education and Research (2018) Map of Industrie 4.0 use cases. https://www.plattform-i40.de/PI40/Navigation/EN/InPra ctice/UseCases/use-cases.html. Accessed 26 Sept 2019

24. Heagney J (2016) Fundamentals of project management, 5th edn. American Management Association, New York

25. Pessl E, Sorko SR, Mayer B (2017) Roadmap Industry 4.0implementation guideline for enterprises. IJSTS 5(6):193. https ://doi.org/10.11648/j.ijsts.20170506.14

26. Technische Universität Darmstadt (2015) Generisches Vorgehensmodell zur Einführung von Industrie 4.0 in mittelständischen Unternehmen der Serienfertigung: abschlussbericht des Fachgebietes Datenverarbeitung in der Konstruktion des Projektes CypIFlex
27. Geleç E, Kern M, Schneider B et al (2017) Metamorphose zur intelligenten und vernetzen Fabrik. In: Weinert N, Plank M, Ullrich A (eds) Metamorphose zur intelligenten und vernetzten Fabrik: ergebnisse des Verbundforschungsprojekts MetamoFAB, vol 46. Springer Vieweg, Berlin, pp 39-120

28. Bechtold J, Kern A, Lauenstein C et al (2014) Industry 4.0-the Capgemini consulting view. Capgemini Consult 31:32-33

29. Hübner M, Liebrecht C, Malessa N et al (2017) Vorgehensmodell zur Einführung von Industrie 4.0: vorstellung eines Vorgehensmodells zur bedarfsgerechten Einführung von Industrie 4.0-Methoden. wt. Werkstattstechnik Online 4:266-272

30. Merz SL, Siepmann D Industrie 4.0-vorgehensmodell für die einführung. In: Roth A (ed) Einführung und umsetzung von Industrie 4.0. Springer Gabler, Leinfelden-Echterdingen, pp 83-110

31. Seiter M, Bayrle C, Berlin S et al (2016) Roadmap Industrie 4.0: ihr Weg zur erfolgreichen Umsetzung von Industrie 4.0. Tredition $\mathrm{GmbH}$, Hamburg

32. Ōno T, Bodek N (2008) Toyota production system: beyond largescale production, [Reprinted]. Productivity Press, New York

33. Erlach K (2013) Value stream design: the way towards a lean factory. Springer, Berlin

34. Köster K (2009) International project management. Sage Publications, London

35. Zimmermann V (2016) SMEs and digitalisation: the current position, recent developments and challenges. KfW Res Focus Econ 138:1-7

36. Plattform Industrie 4.0 (2018) Map of Industrie 4.0 use cases. https://www.acatech.de/publikation/einordnung-der-beispiele-derindustrie-4-0-landkarte-in-die-anwendungsszenarien/. Accessed 19 July 2019

Publisher's Note Springer Nature remains neutral with regard to jurisdictional claims in published maps and institutional affiliations. 